\title{
EXPANSÃO DO ENSINO SUPERIOR: CONTEXTOS, DESAFIOS, POSSIBILIDADES ${ }^{1}$
}

\author{
Antônio Joaquim SeVerino*
}

Recebido em: 25 de março de 2009

Aprovado em: 10 de maio de 2009

\begin{abstract}
* Prof ${ }^{0}$ titular de Filosofia da Educação, Faculdade de Educação da USP; é bacharel e mestre em Filosofia pela Universidade Católica de Louvain, Bélgica; Dr. em Filosofia pela PUC de São Paulo. Livre-docente em Filosofia da Educação pela USP. Seus estudos e pesquisas atuais situam-se no âmbito da filosofia e da filosofia da educação. E-mail: ajsev@uol.com.br
\end{abstract}

Resumo: Partindo de uma leitura do contexto histórico-social que a Universidade brasileira está atravessando no momento, o trabalho argumenta em favor de uma imprescindível articulação entre ensino, pesquisa e extensão. Defende a idéia da indissociabilidade entre essas três funções, concebendo-a como exigência intrínseca para a constituição de uma universidade que possa ser realmente útil para a sociedade brasileira, neste momento histórico novo, diferente e desafiador que está vivendo. Uma universidade que se comprometida com a produção do conhecimento através da prática da pesquisa, poderá desenvolver, com êxito, sua tarefa pedagógica de ensino e sua tarefa social de extensão, tornando-se centro energético de transformação da sociedade, contribuindo para a construção da democracia e da cidadania, mediante a consolidação de uma nova consciência social.

Palavras-chave: Universidade. Conhecimento. Pesquisa. Extensão. Cidadania.

\section{THE EXPANSION OF HIGHER EDUCATION: CONTEXTS, CHALLENGES AND POSSIBILITIES}

Abstract: This paper argues in favor of an essential articulation between teaching, research and extension activities, based on the social-historical context that the Brazilian University is going through at the moment. It defends the idea of the indivisibility of these three functions, conceiving it as an intrinsic requirement for the constitution of a university that is truly useful for the Brazilian society in this new, different and challenging historical moment that it is going through. A university that is committed to the production of knowledge, through the practice of research, will be able to successfully develop its pedagogical role in teaching as well as its social task of extension, becoming an energetic center of social transformation, contributing to the construction of democracy and citizenship, through the consolidation of a new social conscience.

Keywords: University. Knowledge. Research. Extension. Citizenship.

\section{Introdução}

O Brasil está na iminência de ter mais uma reforma universitária, desta feita com um perfil que se anuncia muito marcado pelas configurações do neo-liberalismo econômico e cultural. Com a comunidade nacional bastante desmobilizada, no contexto da atual conjuntura política e social do país, corre-

1 Este texto constitui a base da palestra apresentada no VI Fórum dos Pro-Reitores de Graduação da Região Sudeste (FORGRAD), que aconteceu em Campinas, aos 15 de fevereiro de 2009. 
se o risco de se perder muitas das conquistas já obtidas nos últimos tempos, agravando ainda mais a situação do ensino superior no país. Por isso mesmo, impõe-se o debate sobre o sentido de uma universidade que, funcionária do conhecimento, pudesse colocá-lo a serviço da sociedade. Comprometida com o conhecimento, ela o será também, por decorrência, com a extensão e a pesquisa, tanto quanto com o ensino. Muitas são as dificuldades que a universidade brasileira encontra em sua inserção histórica na sociedade brasileira, sob os diversos condicionamentos políticos, econômicos e sociais. Mas enfrenta também problemas no interior de sua esfera específica, como lugar de produção, sistematização e disseminação do conhecimento, problemas ainda não devidamente superados. Continua desafio para a universidade brasileira rever com criticidade, criatividade e competência, sua relação com o conhecimento, tratando-o como processo e não como produto, equacionando-o como mediação da educação e esta, como mediação da cidadania e da democracia.

A significação da Universidade se dilui num emaranhado de idéias e proposições que vêm sendo formuladas, no momento atual, como indicação de que a humanidade teria entrado numa nova era, que superaria tudo que havia construído e acumulado. Com efeito, tornou-se discurso corrente e recorrente a afirmação incisiva de que estaríamos vivendo hoje, no limiar do terceiro milênio, um mundo totalmente diferente daquele projetado pela visão iluminista da modernidade e destinado à realização de uma sociedade utópica. Chega-se ao ponto de se afirmar que a história teria terminado, uma vez que a civilização humana teria alcançado o patamar mais alto do progresso possível para a humanidade. Já se encontrariam realizadas todas as possibilidades de aperfeiçoamento, de aprimoramento de nossas condições de vida individual e social. O modelo de existência humana não é mais um ponto no horizonte futuro, mas já está disponível no presente, faltando apenas que cada pessoa ou cada grupo a ele se ajustasse. Estaríamos vivendo um momento de plena revolução tecnológica, capaz de lidar com a produção e transmissão de informações em extraordinária velocidade, num processo de planetarização não só da cultura mas também da economia e da política. Tratar-se-ia de um momento marcado pelo privilegiamento da iniciativa privada, pela minimalização da ingerência do Estado nos negócios humanos, pela maximalização das leis do mercado, pela ruptura de todas as fronteiras e barreiras entre estados e mercados. No plano mais especificamente filosófico, estaria em pauta uma crítica cerrada às formas de expressão da razão teórica da modernidade, propondo-se a desconstrução de todos os discursos por ela produzidos, todos colocados sob suspeita, inclusive aqueles da própria ciência. Este mundo novo dispensa a Universidade tradi- 
cional, forjada à luz das referências da modernidade, uma de suas expressões mais arrematadas.

Dada essa situação, o lugar e o papel da educação precisam ser continua e expressamente retomados e redimensionados. Com efeito, o compromisso ético e político da educação, por assim dizer, se acirra nas coordenadas historico-sociais em que nos encontramos. Isto porque as forças de dominação, de degradação, de opressão e de alienação, se consolidaram nas estruturas sociais, econômicas e culturais. As condições de trabalho são ainda muito degradantes, as relações de poder muito opressivas e a vivência cultural precária e alienante. A distribuição dos bens naturais, dos bens políticos e dos bens simbólicos, muito desigual. Em outras palavras, as condições atuais de existência da humanidade, traduzidas pela efetivação de suas mediações objetivas, são extremamente injustas e desumanizadoras. Tais condições se mostram muito agravadas no contexto histórico-social do terceiro mundo, assumindo características particularmente críticas na América Latina.

É neste contexto estrutural e conjuntural que se impõe olhar para a realidade da educação universitária brasileira, seja para identificar seus desafios e buscar caminhos de superação.

\section{Um retrato sem retoques}

Sem dúvida, o núcleo forte da vida universitária, o seu pólo magnético, a sua razão de ser, é o ensino de graduação. Segundo o Censo, o Brasil conta hoje com 2.281 IES, das quais 183 são universidades, 120 Centros Universitários e 1978 são faculdades isoladas. Estes números representam uma expansão em relação a 2006 de apenas $0,5 \%$, último índice de uma série que vem apresentando uma tendência decrescente desde 2003. Contrariando a tendência dos anos anteriores, desta feita o maior crescimento se deu nas universidades $[2,8 \%]$, categoria que nos anos anteriores sempre apresentou a menor taxa de crescimento. Cabe observar, no entanto, que não obstante esse decréscimo do número de Instituições, a oferta de vagas, o número de ingressos e de matrículas tiveram um crescimento maior. É interessante observar que o Censo se desdobra em três grandes segmentos: o do ensino presencial, o do ensino técnico e o do ensino a distância. Estes dois últimos segmentos constituem as novas meninas-dos-olhos da política educacional do momento.

O país conta com 4.880.381 matrículas das quais 2.644.187 estão feitas nas universidades, 680.938 nos Centros Universitários e 1.555.256 nas Faculdades Isoladas. 
Das 183 universidades, 96 são públicas [52,5\%] e 87, privadas [47,5\%]; já dos 120 Centros Universitários 116 são privados [96,7\%] contra 4 públicos, e das 1978 faculdades, 1829 são privadas [92,5\%] e 149 públicas [7,5\%].

No cômputo geral, das 2281 IES, $89 \%$ são instituições privadas e apenas $11 \%$ públicas, sendo $4,6 \%$ federais, $3,6 \%$ estaduais e $2,7 \%$ municipais.

Funcionaram em 2007, 23.488 cursos presenciais de graduação, o que representa um aumento de $6,8 \%$ em relação a 2006. O crescimento médio de IES públicas, federais e municipais, bem como das privadas foi em média de $8,5 \%$, mas as públicas estaduais tiveram um decréscimo na oferta de cursos de $7,7 \%$. É de se registrar ainda que, embora o maior aumento de Instituições seja o das faculdades, são as Universidades que respondem pela maior quantidade de cursos e de alunos.

Em 2007, foram oferecidas 2.823.942 vagas nos vestibulares, o que representou um aumento de 194.344 vagas em relação a 2006, ou seja, 7,4\%. Novamente constatou-se queda das vagas nas universidades públicas estaduais, de 9,6\%. Mas o aumento da oferta de vagas não representou aumento proporcional do número de ingresso, o que resultou na ocorrência de 1.341.987 vagas ociosas.

Concorreram às vagas 5.191 .760 candidatos; ingressaram 1.481 .955 alunos para as 2823.942 vagas oferecidas; portanto, apenas $52,5 \%$ das vagas foram ocupadas.

Por outro lado o censo de 2007 demonstra que continua elevada a taxa de evasão de alunos. Em 2007, esta taxa foi de $41,9 \%$, sendo $27,4 \%$ no ensino público federal, $36,2 \%$ no ensino público estadual , 37,6\% no ensino público municipal,. 44,6\% no ensino privado.

O que chama a atenção nos dados deste Censo, com um perfil que se mantém bastante igual nos últimos anos? Em primeiro lugar, a grandiosidade dos números envolvidos e a complexidade dos dados. Por mais que possamos nos sentir ainda inseguros com a precisão desses dados, dispomos, sem dúvida, de um bom retrato da realidade de nosso ensino superior. Em segundo lugar, de um ponto de vista puramente quantitativo, vemos confirmada a expansão do ensino superior no país, embora em ritmo mais lento. O que, evidentemente, é, em tese, um aspecto muito positivo, pois o país precisaria dobrar sua população universitária.

Mas além disso, este crescimento revela algumas distorções. A expansão do ensino superior, do ponto de vista institucional, reforça sua opção preferencial pelo modelo da faculdade isolada. Tanto que este modelo prevalece na configuração institucional do sistema. No entanto, é bem verdade que a maioria das matrículas [54\%] se encontra nas Universidades, 14\% nos Centros 
Universitários e apenas 32\% nas Faculdades. Por que será que priorizamos essa forma de distribuição dos alunos, um número menor deles em um número tão maior de pequenas instituições? Certamente, não é para garantir alta especialização.

O alto índice de evasão é outra distorção incompreensível e injustificável, pela irracionalidade e desperdício que ele expressa. Se acrescentarmos a esse fenômeno o número de vagas não preenchidas bem como o número de formados que não atuam no seu campo de formação, temos então um quadro desolador e desafiante, ficando difícil entender como convivemos com essa situação, dado seu ônus econômico, científico e cultural para a nação. Porque o sistema se revela impotente para superar esse problema e reverter esse quadro? Estaria aí, tornado crônico, mais um fracasso de nossa política educacional?

É também outro fato preocupante a distribuição desigual das IES pelas diversas regiões do país, o quadro apresentando um grande desequilíbrio regional. Ocorre uma verdadeira sudestificação da educação superior, na expressão de Ristoff (2008, p. 43), pois os quatro estados da Região Sudeste acumulam cerca de $50 \%$ das IES, dos cursos e das matrículas do Brasil.

Por outro lado, a ampliação do acesso não tem significado necessariamente ampliação de oportunidades. A maioria das matrículas se dá em alguns poucos cursos, (Administração, Direito, Pedagogia) com hipertrofia da oferta de vagas sem maior impacto na inserção social, "revelando uma despreocupação nacional crônica com um projeto nacional de desenvolvimento e com uma imagem de futuro para o país." (RISTOFF, 2008, p. 43)

São, pois, ainda muito numerosos os desafios político-sociais que envolvem a realidade da educação universitária no país. Mas, por maiores que sejam esses desafios em sua dimensão quantitativa, não se pode aguardar sua solução para se cuidar igualmente daqueles desafios de natureza qualitativa, relacionados aos aspectos da vida acadêmica no interior das instituições e nos processos propriamente pedagógicos da formação universitária

Este perfil, resumido assim em grandes pinceladas, parece revelar um profundo comprometimento da consistência da Universidade brasileira. Ele confirma e reforça minha constatação, ao longo destas 4 décadas, de que a finalidade maior e central da Universidade está, a cada dia que passa, cada vez mais abalada, desconsiderada, está perdendo relevância, minada que está por vários movimentos e muitas contradições. Caracterizam-se entendimentos teóricos e direcionamentos práticos divergentes por parte dos responsáveis pela gestão macro e micro do ensino superior no país. 


\section{Desafios e perspectivas}

De um lado, buscando criticar o modelo vigente e superar seus problemas, alguns tendem a transformar a Universidade numa instituição que só privilegiaria a pesquisa, que priorizaria excessivamente a pesquisa, desprestigiando seu papel educativo frente à juventude considerando menor a tarefa do ensino de graduação, passando a investir pesado no ensino de pós-graduação, identificado fundamentalmente com a realização sistemática da pesquisa. Se é verdade que esta tendência, que se manifesta mais nas universidades públicas, é uma força importante na história do ensino superior no Brasil, representando assim uma intenção positiva, já que a dimensão da pesquisa era quase que inexistente na nossa tradição universitária, não se pode desconsiderar o risco de elitização que ela traz em seu bojo, o risco de uma postura altaneira e arrogante que acabará impedindo a Universidade de dar à sociedade o retorno que ela espera e merece, com toda legitimidade. Processo que, independentemente de sua qualidade intrínseca, desvirtua a própria razão de ser da Universidade.

De outro lado, outros vêem a superação dos problemas entendendo como único papel da Universidade a preparação de técnicos a serviço do mercado de trabalho, numa postura meramente profissionalizante, desconhecendo a necessidade não só da formação científica mas também de uma densa e consistente formação política. São forças centrípetas que tendem a fazer com que o ensino superior se feche sobre si mesmo, como um redemoinho. Nunca é demais insistir: cabe à universidade como instituição como lugar específico do ensino superior dedicar-se à formação do cidadão autêntico, pois seu papel mais substantivo vai muito além da formação do profissional, do técnico e do especialista. Por mais que os resultados históricos não tenham correspondido a essa expectativa, isso não compromete sua finalidade intrínseca, formadora que precisa ser da consciência social que é a única sustentação de um projeto político minimamente equitativo, justo e emancipador.

Mas a universidade brasileira está acossada também por forças externas, forças do contexto que questionam sua autonomia, pressionando-a a se desviar de seus compromissos mais substantivos. Vive uma dura orfandade, sitiada por todos os lados.

É pressionada de fora pelas injunções de uma dinâmica social escrava do mercado, onde só conta o valor de troca, onde tudo se transforma em mercadoria para um consumo desvairado. Essa dinâmica mercantil induz, por sua vez, uma política atrelada a interesses menores, descompromissados com a construção do bem comum. A humanidade parece caminhar, cada dia mais, 
para uma condição na qual o econômico prevalece sobre o político e sobre o cultural. E um econômico que tende a reduzir-se ao financeiro. É que o bem se desenha, ao vivo e a cores, a atual crise mundial. Na verdade, uma crise anunciada, preparada e manipulada. Um terremoto análogo àquele provocado pelo ajuste das placas tectônicas que constituem a crosta terrestre: trata-se de um ajustar-se das partes. O que está em jogo aqui é um ajuste das próprias condições do mundo humano para que se solidifique uma nova configuração do social, subalternizando-o, de vez, ao mercado. Uma crise para acabar com resistências que ainda impediam essa reconfiguração. Não deixa de ser sintomático que esta seja uma crise provocada, alimentada e sustentada pelo mercado financeiro, fina flor do capitalismo vigente na atualidade. O econômico prevalecendo sobre o político e se delineando como mero jogo financeiro do capital. A partir desta crise, o Estado, outrora representante legitimado do poder político, passa a ser mero agente executivo do econômico financeirizado.

Esta nova configuração do mundo, que se apresenta como se fosse uma ordem nova, vai impondo a lógica do mercado a todas as dimensões da vida humana. A educação, em geral, e a educação universitária, em particular, não passam incólumes sob os efeitos de sua intervenção. Mas as conseqüências são drásticas. Vendendo seus encantos como as sereias vendiam suas melodiosas músicas, promessas que não podem ser cumpridas, o novo poder hipnotiza a juventude, constrange os educadores e chantageia os gestores. Seus intelectuais orgânicos desmontam todas as críticas, desqualificam todos aqueles que ousam se opor a suas propostas.

A lógica do mercado que impõe uma funcionalidade econômica, utilitarista. Induz à competitividade desenfreada. Propõe a aquisição de competências não para saber fazer, mas para competir, conhecimento utilitarista, instrumental, performance competitiva. Acaba ocorrendo uma colonização da política educacional pelos imperativos da economia.

Centrada no desempenho dos indivíduos, visto como um agregado de competidores pelos postos do mercado de trabalho e não parceiros na condução de um projeto. Cada um deve construir seu port-folio de competências individuais.

Aqui o impacto não só aquele decorrente da mercantilização dos serviços educacionais, mas pior ainda, a defesa, a impregnação de uma ideologia individualista, consumista e idealista. Os jovens não saem formados do ensino superior, mas deformados, com uma visão medíocre e egoísta da vida social e de sua participação nela.

Mas, além disso, internamente, a vida acadêmica é marcada por muitas contradições que, por assim dizer, comprometem a própria razão de ser da uni- 
versidade, a mesquinhez, a miopia, o corporativismo, o mandonismo, o autoritarismo, o dogmatismo prevalecem e contaminam todo o organismo universitário.

É neste contexto de um modelo societário marcado pela lógica do mercado, com suas pesadas conseqüencias para a educação universitária que se pode fazer uma leitura do chamado Processo de Bolonha, iniciativa política da União Européia para uma significativa reorganização de seu sistema universitária. Trata-se a criação do Espaço Europeu de Ensino Superior. Na verdade, é a adoção do modelo inglês para formar uma educação européia. A Europa continuaria querendo construir um império integrado, hoje usando o conhecimento como a nova arma.

Estaria ocorrendo uma transição do paradigma do ensino para a aprendizagem. O indivíduo, como aprendiz, é que é responsável pela sua formação, não é o processo em si do ensino. Também não mais se pensam por políticas públicas, mas por estratégias governamentais. Está em processo a desregulação da educação pública, o Estado passa a ser apenas um avaliador, um supervisor, uma agência de controle e avaliação. Tudo passa por uma estratégia econômica de gestão.

Trago à baila a referência ao processo de Bolonha pela reconhecida importância que a experiência européia tem para nós. Sem dúvida, exercerá uma grande influência, nem sempre recebida e incorporada com o devido distanciamento crítico. Estamos aqui e agora diante de um novo emblema. A universidade ocidental nasceu em Bolonha e corre o risco de lá também perecer.

Por tudo isso, muitos desafios permanecem e algumas possibilidades se apresentam. Sem dúvida, é equívoca a tendência de privilegiar a pesquisa, a reduzir o papel da universidade àquele de fazer pesquisa, como se fosse a única atividade a ser prestigiada. Desconsiderar a necessidade da pesquisa como postura investigativa é condenar o ensino superior à mediocridade, comprometendo sua competência e responsabilidade em lidar com o conhecimento novo, obstruindo sua criatividade para inovar e sua criticidade para avaliar a história. Transforma-se numa instituição puramente certificadora. Quanto à prática da pesquisa nos processos de ensino e aprendizagem na Universidade, defendo a posição de que, na Universidade, esses processos só serão significativos se forem sustentados por uma permanente atividade de construção do conhecimento. O professor universitário precisa da prática da pesquisa para ensinar eficazmente; o aluno precisa dela para aprender eficaz e significativamente; a comunidade precisa da pesquisa para poder dispor de produtos do conhecimento; e a Universidade precisa da pesquisa para ser mediadora da educação. $\mathrm{O}$ aluno só consegue aprender significativamente se sua aprendi- 
zagem se der como construção do conhecimento. Mas estamos aqui falando de mediações, a postura investigativa é um meio, uma mediação, em vista de uma finalidade, no caso, um bom ensino, uma boa extensão. Por isso mesmo, ao mesmo tempo que se trata de valorizar a perspectiva daquela formação que tradicionalmente encarnamos no bacharelado, não se pode perder de vista que não estamos querendo formar cientistas no sentido estrito e restrito da expressão.

Na Universidade, ensino, pesquisa e extensão efetivamente se articulam, mas a partir da pesquisa, ou seja, só se aprende, só se ensina, pesquisando, construindo conhecimento; só se presta serviços à comunidade, se tais serviços nascerem e se nutrirem da pesquisa. Impõe-se partir de uma equação de acordo com a qual educar (ensinar e aprender) significa conhecer; e conhecer, por sua vez, significa construir o objeto; mas construir o objeto significa pesquisar. Por isso mesmo, também na Universidade, a aprendizagem, a docência, a ensinagem, só serão significativas se forem sustentadas por uma permanente atividade de construção do conhecimento. Ambos, professor e aluno, precisam da pesquisa para bem conduzir um ensino eficaz e para ter um aprendizado significativo.

Por outro lado, e agora me referindo à perspectiva da Licenciatura, não se pode desconsiderar quando está em pauta a natureza e a finalidade do ensino superior a questão do ensino e da formação do educador. Primeiramente em decorrência do envolvimento intrínseco do ensino superior com a educação em geral.

O compromisso da Universidade com o ensino básico não é só aquele decorrente de sua atribuição institucional, daquela tarefa técnica de formar os professores, como profissionais do ensino. Ele é muito mais profundo e radical. Trata-se de um compromisso ético-político com a educação, mola propulsora do processo civilizatório. Não se trata de uma opção da Universidade se vai se preocupar com isso ou não. Deixar de assumir responsabilidades diretas e incisivas em relação a essa problemática é uma traição a seu próprio destino. Ela precisa ser lugar prioritário de se pensar modelos e caminhos da educação básica do país. Como não se abalar com os dados trazidos pelo Censo de 2007 ao revelarem a grave crise pela qual está passando a formação de professores? Como conviver com a precariedade de nossos cursos de Licenciatura e Pedagogia, como se nada tivessem a ver conosco? Todos sabemos muito bem que o fator predominante dessa crise vem da ausência de uma política pública mais consistente por parte do Estado mas quem vive dentro dos muros da Universidades bem sabe o quanto a Licenciatura é desprestigiada, conforme depoimento recente do próprio Ministro da Educação, ao justificar a criação da Bolsa de Iniciação à Docência.(TAKAHASHI; PINHO, 2009, p. C8) 
À universidade, cuja atribuição, ao preparar os profissionais nos diversos campos da cultura, não é repassar uma instrução técnica, mas assegurar a formação integral dos estudantes, cabe uma responsabilidade social da qual decorrem exigências específicas:

Uma lida rigorosa com o conhecimento, donde a necessidade do investimento na prática da pesquisa, no domínio de metodologias especializadas de investigação, na consolidação da pós-graduação como escola de construção do saber, no compromisso com a competência técnica.

Um compromisso ético-político: o profissional a ser formado é antes de tudo um ser humano, que precisa tornar-se sensível à dignidade humana bem como um cidadão que precisa se comprometer com a democratização das relações sociais, dotando-se de uma nova consciência social. E pouco importa qual seja sua área de profissionalização.

Reencontramos aqui a dimensão igualmente imprescindível da extensão no processo integral da formação universitária. Com efeito, é graças à extensão que o pedagógico ganha sua dimensão política, porque a formação do universitário pressupõe também uma inserção no social, despertando-o para o entendimento do papel de todo saber na instauração do social. E isso não se dá apenas pela mediação do conceito, em que pese a imprescindibilidade do saber teórico sobre a dinâmica do processo e das relações políticas. É que se espera do ensino superior não apenas o conhecimento técnico-científico, mas também uma nova consciência social por parte dos profissionais formados pela Universidade. A formação universitária, com efeito, é o locus mais apropriado, especificamente destinado para esta tomada de consciência, só a pedagogia universitária, em razão de suas características especiais, pode interpelar o jovem quanto ao necessário compromisso político. Esta interpelação se dá pelo saber, eis que cabe agora ao saber equacionar o poder

Deste modo, a extensão tem grande alcance pedagógico, levando o jovem estudante a vivenciar sua realidade social. É por meio dela que o sujeito/aprendiz irá formando sua nova consciência social. A extensão cria então um espaço de formação pedagógica, numa dimensão própria e insubstituível.

Quando a formação universitária se limita ao ensino como mero repasse de informações ou conhecimentos está colocando o saber a serviço apenas do fazer. Eis aí a idéia implícita quando se vê seu objetivo apenas como profissionalização. Por melhor que seja o domínio que se repassará ao universitário dos conhecimentos científicos e das habilidades técnicas, qualificando-o para ser um competente profissional, isto não é suficiente. Ele nunca sairá da Universidade apenas como um profissional, como um puro agente técnico. 


\section{Conclusão}

Essas exigências se desdobram em implicações e demandam mudanças na postura acadêmica e no modo de conceber e de implementar o currículo e a prática pedagógica da Universidade.

Antes de mais nada, impõem-se uma concepção e uma prática do planejamento curricular e pedagógico do ensino superior que envolvam um complexo investimento. Primeiramente, é preciso garantir uma justificativa políticoeducacional do processo. Trata-se de mostrar aos estudantes que o conhecimento é a única ferramenta de que o homem dispõe para cuidar da orientação de sua existência, sob qualquer ângulo que ela seja encarada. A habilidade em lidar com o conhecimento como ferramenta de intervenção no mundo natural e no mundo social é pré-requisito imprescindível para qualquer profissão, em qualquer área de atuação dos sujeitos humanos, mas também para a condução da existência humanizada. Por isso mesmo, todos os currículos universitários precisam contar também com componentes de natureza filosófica, capazes de assegurar o esclarecimento crítico acerca das relações entre o epistêmico e o social.

Em seguida, é preciso assegurar igualmente uma fundamentação epistemológica, ou seja, garantir ao aprendiz o domínio do próprio processo de construção do conhecimento, consolidando-se a convicção quanto ao caráter construtivo desse processo, superando-se todas as outras crenças epistemológicas arraigadas em nossa tradição filosófica e cultural, de cunho representacionista, intuicionista etc. É pré-requisito imprescindível para que nos tornemos pesquisadores a explicitação dos processos básicos que emergem na relação sujeito/objeto quando da atividade cognoscitiva. De nada valerá ensinar métodos e técnicas se não se tem presente a significação epistêmica do processo investigativo.

Mas sobre esse lastro epistemológico, é preciso colocar à disposição dos estudantes uma metodologia técnico-científica para o trabalho investigativo específico de cada área. Com efeito, essa etapa não deve ser identificada ou confundida com a metodologia do trabalho científico, pois ela trata dos meios de investigação aplicada em cada campo de conhecimento.

E é sobre essa base ganha sentido a inclusão de componente curricular mediador de estratégia didático-metodológica, que cabe se designar como a metodologia do trabalho científico, onde se tratará da iniciação às práticas do trabalho acadêmico, estratégia geral de interesse de todos os estudantes, independentemente de sua área de formação.

O futuro da Universidade brasileira está na dependência da sua transformação em centro de ensino e extensão fundados na pesquisa. Só assim responderá aos 
desafios da alta modernidade. Construir essa Universidade do futuro, a meu ver, implica investir na Universidade do presente. Mas não basta a incorporação mecânica dos sofisticados instrumentos das novas tecnologias informacionais para se garantir uma Universidade de qualidade, para assegurar o acesso e o uso otimizado dos recursos. Se não há como ignorar e deixar de lado toda a potencialidade que as novas tecnologias informacionais representam para a educação em geral, e para a Universidade em particular, toda essa tecnologia precisa ser vista como ferramenta corriqueira como o foram um dia a régua e o compasso. Mas, não há como acreditar que essas tecnologias, por mais sofisticadas que sejam, poderão substituir o lento processo de ensino/aprendizagem que se dá via construção do conhecimento. Meios potencializadores são necessários e bem-vindos, mas continuam sendo meios, à espera de quem possa explorá-los como sujeitos competentes, criativos e críticos. Não há também como confundir a capacidade de transmitir informações, o que essa tecnologia permite fazer com grande eficiência, com compartilhar o processo de produção de conhecimentos, o que demanda muito mais do que um repasse eficaz de dados. Em se tratando de conhecimento, o que está em jogo é a formação do sujeito e não sua mera instrução.

Uma sociedade como a sociedade brasileira, ainda marcada por tantas carências, em todos os planos da existência histórica de sua população, depende muito da contribuição do conhecimento, daquele conhecimento que tenha a ver com sua realidade. Trata-se de ferramenta imprescindível e extremamente valiosa na superação de todas essas limitações. Mas tem que ser um conhecimento desvelador dessa realidade. A insuficiência da contribuição do ensino superior no Brasil para a superação de todas as lacunas que a sociedade tem enfrentado decorre, em muito, do fato de que não vem efetivamente construindo um conhecimento pertinente e relevante, deixando-se levar por uma prática muito retórica e meramente repetitiva. Como podemos ver, trata-se de mudar a nossa maneira de lidar com o próprio conhecimento.

\section{Referências}

ABREU, M. Célia; MASETTO, Marcos. O professor universitário em aula: prática e princípios teóricos. São Paulo: Autores Associados, 1990.

BERBEL, Neusi A. N. Metodologia do ensino superior: realidade e significado. Campinas: Papirus, 1989. 
BITTAR, Mariluce; OLIVEIRA, João F. de; MOROSINI, Marília (Orgs.). Educação superior no Brasil: 10 anos pós-LDB. Brasília: INEP, 2008.

BREGLIA, Vera Lucia A. Graduação, formação e pesquisa: entre o discurso e as práticas. Caxambu: Anped, 2004.

CALAZANS, Julieta (Org.). Iniciação científica: construindo o pensamento crítico. São Paulo: Cortez, 1999.

CARVALHO, Ana M. P. de. A formação do professor e a prática de ensino. São Paulo: Pioneira, 1988.

COÊLHO, Ildeu. Universidade e formação de professores. In: GUIMARÃES, Valter S. Formar para o mercado ou para a autonomia? O papel da universidade. Campinas: Papirus, 2006. p. 43-63.

GOERGEN, Pedro A crise de identidade da universidade moderna. In: SANTOS FILHO, C; MORAES, S. (Orgs.). Escola e universidade na pósmodernidade. Campinas: Mercado de Letras/Fapesp, 2000.

MASETTO, Marcos T. (Org.). Docência na universidade. Campinas: Papirus, 1998.

PACHANE, Graziela G. Políticas de formação pedagógica do professor universitário: reflexões a partir de uma experiência. Caxambu: Anped, 2004.

PEREIRA, Elisabete M. de A. (Org.). Universidade e educação geral: para além da especialização. Campinas: Alínea, [s.d.]. (Col. Educação em Debate).

PIMENTA, Selma G.; ANASTASIOU, Lea das G. C. Docência no ensino superior. São Paulo: Cortez, 2003. (Coleção Docência em Formação).

RISTOFF, Dilvo. Educação superior no Brasil: 10 anos pós-LDB: da expansão à democratização. In: BITTAR, Mariluce; OLIVEIRA, João F. de; MOROSINI, Marília (Orgs.). Educação superior no Brasil: 10 anos pós-LDB. Brasília: INEP, 2008. p. 39-50. 
SEVERINO, Antônio J. Metodologia do trabalho científico. 23. ed. São Paulo: Cortez, 2007.

SILVA JR., João dos Reis; SGUISSARDI, Valdemar. Novas faces da educação superior no Brasil. 2. ed. São Paulo: Cortez Editora/CDAPH_ IFAN, 2001.

TAKAHASHI, Fábio; PINHO, Angela. País forma cada vez menos professores. Folha de S. Paulo, São Paulo, 3 fev. 2009. p. C8.

TAVARES, José. Formação e inovação no ensino superior. Porto: Porto, 2003. (Coleção CIDInE, v. 15).

TAVARES, José; SANTIAGO, Rui A. (Orgs.). Ensino superior: (in)sucexxo acadêmico. Porto: Porto, 2000. (Coleção CIDInE, v. 13). 